OPEN ACCESS

Edited by:

$\mathrm{Li} L \mathrm{Li}$

Cornell University,

United States

Reviewed by:

Sang-Soo Kwak,

Korea Research Institute of

Bioscience and Biotechnology

(KRIBB), South Korea

Changfu Zhu,

Changchun Normal University,

China

*Correspondence:

Claudia E. Osorio

claudia.osorio@cgna.cl

Specialty section:

This article was submitted to

Plant Metabolism and

Chemodiversity,

a section of the journal

Frontiers in Plant Science

Received: 17 May 2019 Accepted: 05 September 2019

Published: 04 October 2019

Citation:

Osorio CE (2019) The Role of Orange Gene in Carotenoid

Accumulation: Manipulating

Chromoplasts Toward a

Colored Future.

Front. Plant Sci. 10:1235.

doi: 10.3389/fp/s.2019.01235

\section{The Role of Orange Gene in Carotenoid Accumulation: Manipulating Chromoplasts Toward a Colored Future}

\author{
Claudia E. Osorio* \\ Agriaquaculture Nutritional Genomic Center, CGNA, Temuco, Chile
}

Carotenoids are isoprenoid pigments synthesized in plants, algae, and photosynthetic bacteria and fungus. Their role is essential in light capture, photoprotection, pollinator attraction, and phytohormone production. Furthermore, they can regulate plant development when they are processed as small signaling molecules. Due to their importance for human health, as promoters of the immune system and antioxidant activity, carotenoids have been used in the pharmaceutical, food, and nutraceutical industries. Regulation of carotenoid synthesis and accumulation has been extensively studied. Excellent work has been done unraveling the mode of action of phytoene synthase (PSY), a rate-limiting enzyme of carotenoid biosynthesis pathway, in model species and staple crops. Lately, interest has been turned to Orange protein and its interaction with PSY during carotenoid biosynthesis. Discovered as a dominant mutation in Brassica oleracea, Orange protein regulates carotenoid accumulation by posttranscriptionally regulating PSY, promoting the formation of carotenoid-sequestering structures, and also preventing carotenoid degradation. Furthermore, Orange protein contributes to homeostasis regulation, improving plant tolerance to abiotic stress. In this mini review, the focus is made on recent evidence that elucidates Orange protein mode of action and expression in different plant species. Additionally, strategies are proposed to modify Orange gene by utilization of genome editing techniques. A better understanding of carotenoid biosynthesis and accumulation will lead to a positive impact on the development of healthy food for a growing population.

Keywords: carotenoid accumulation, Orange gene, OR, Plastid, Orange protein, protein interaction, phytoene synthase

Carotenoids are isoprenoid pigments, synthesized in all photosynthetic organisms, such as bacteria, algae, plants, and some fungi (Howitt and Pogson, 2006; Yahia et al., 2017; Young and Pallett, 2017). In higher plants, carotenoids are recognized for their essential role in photosynthesis and photoprotection (Ramel et al., 2012; Domonkos et al., 2013; Niyogi and Truong, 2013). Carotenoids also are precursors for abscisic acid (ABA) and strigolactone synthesis (Crozier, 2000; GomezRoldan et al., 2008), which has been demonstrated to be involved in responses to abiotic stresses, including high temperature and drought (Li et al., 2008a; Li et al., 2008b; Park et al., 2016) and shoot branching and plant signaling, respectively (Yoneyama et al., 2018). In mammals, carotenoids constitute an essential group of nutrients, which function as vitamin A precursors, stimulating immune system and antioxidant activity (Hughes, 1999; Cazzonelli and Pogson, 2010). Studies have 
demonstrated that in humans (Seddon et al., 1994; Snodderly, 1995; Fiedor and Burda, 2014) carotenoids have an important antioxidant and anticancer activity, as well as protector agents against macular degeneration of elderly people (Beatty et al., 2000). Because of their multiple functions, efforts have been made to elucidate carotenoids synthesis and storage in different plant species, and work has been made to fortify staple crops for carotenoid consumption (Zhu et al., 2018; Tian et al., 2019). Carotenoid accumulation in chromoplasts is the result of three independent processes, carotenoid biosynthesis, degradation, and stable storage, which occur at different developmental plant stages (Li and Yuan, 2013; Nisar et al., 2015). Specific transcription factors establish a tight and precise control of gene expression along carotenoid pathway, allowing biosynthesis and catabolism in accordance with specific organ requirements (Young and Pallett, 2017). In the present article, the focus is made on the role of Orange protein as a regulator of carotenoid accumulation in different plant species and its interaction with phytoene synthase, which has been named a key enzyme in the carotenoid pathway, with special emphasis on efforts to manipulate the Orange gene to stimulate carotenoid accumulation. Strategies to achieve this goal are proposed, considering the recent advances in plant genome editing.

\section{PRESENCE OF ORANGE GENE IN HIGHER PLANTS}

Recognized as a dominant spontaneous mutation in Brassica oleracea, which confers orange color to the influorescence, Orange gene has proven to play an important role in carotenoid accumulation by activating chromoplast differentiation in nongreen tissues (Lu et al., 2006). In cauliflower, the mutant allele consists of a large retrotransposon insertion, with homozygous mutants displaying a dwarf phenotype, which include longer petiole, small curds, and late flowering (Li et al., 2001; Lu et al., 2006). Orange gene $(O R)$ encodes for a protein belonging to the DnaJ cysteine-rich zinc finger protein domain, which is a highly conserved sequence among diverse plant species (Lu et al., 2006; Tzuri et al., 2015; Pulido and Leister, 2018), had positioned Orange protein in the nucleus (Zhou et al., 2011; Kim et al., 2013; Sun et al., 2016), suggesting that interaction with nuclear elements such as transcription factors is required to initiate plastid transition and carotenoid accumulation (Sun et al., 2016). Orthologs of cauliflower wild-type $O R$ have been identified and have been shown to have a positive effect on carotenoid increase exhibiting important responses to environmental stress (Kim et al., 2013; Tzuri et al., 2015; Yuan et al., 2015a; Yuan et al., 2015b). In experiments conducted in Arabidopsis and sweetpotato, expression of orthologs ( $I b O R$ and AtOR, respectively), were able to induce carotenoid accumulation in different tissues, such as sweetpotato plants, rice callus, and rice plants (Kim et al., 2013; Bai et al., 2016), increasing tolerance to $\mathrm{NaCl}$ stress, by moderating oxidation states in transgenic calli. During the postharvest period in potato, expression of Orange stimulates continuous accumulation and stable storage of carotenoids (Li et al., 2012), opening the possibilities to decrease losses during potato storage. In melon, a single mutation of a residue in Orange gene, the golden SNP, produces a change from green to orange flesh in fruits, with carotenoid accumulation from day 30 after anthesis, with no further effects on phenotype (Tzuri et al., 2015), increasing variability in fruits. Isolation and expression of mutated Sorghum bicolor Orange gene in Arabidopsis led to an increase in carotenoid accumulation in calli (Yuan et al., 2015a), with no additional effects on carotenoid metabolic gene expression. In mutant $B$. oleracea, Orange has been associated also with plant growth and development (Zhou et al., 2011). Analysis of the interaction of BoOr and cauliflower eukaryotic release factor 1 protein (eRF1) revealed an antagonist effect, with an increase in the length of the petiole because of suppression of BoeRF1 family genes when BoOr was expressed (Zhou et al., 2011).

\section{ORANGE PROTEIN MODE OF ACTION AND CAROTENOID REGULATION}

Regulation of key biosynthetic genes is a major determinant for carotenoid content (Cong et al., 2009; Vallabhaneni and Wurtzel, 2009; da Silva Messias et al., 2014; Yuan et al., 2015b). In Arabidopsis, AtOr protein is located in plastids, and its $\mathrm{N}$-terminal region interacts directly with phytoene synthase (PSY) to control carotenoid biosynthesis posttranscriptionally (Zhou et al., 2015). Expression of carotenoid biosynthetic genes in $B$. oleracea was not changed by the Orange B. oleracea $(B o O R)$ dominant mutation, with normal levels of PSY expressed during development ( $\mathrm{Li}$ et al., 2001). Natural allelic variations of the Orange gene in melon fruits, $\mathrm{CmOR}^{\mathrm{His}}$ and $\mathrm{CmOR}^{\mathrm{Arg}}$, similarly enhanced carotenoid biosynthesis by posttranscriptionally regulating PSY proteins amounts (Tzuri et al., 2015). In sweetpotato, IbPSY interacts with the IbOr-N fragment, which contains the $\mathrm{N}$-terminal region and the transmembrane domain (Park et al., 2016), which have been reported to mediate protein-protein interaction (Zhou et al., 2015). Later studies had proven also that sweetpotato and melon orange protein (IbOr and CmOr) interact with PSY providing holdase activity (Park et al., 2016), protecting PSY under heat and oxidative stress conditions, keeping the protein structure and preventing aggregation by protein association. It has been also hypothesized that Orange protein function is to keep the levels and efficiency of photosystem II and chlorophyll under high-temperature conditions (Kim et al., 2013; Wang et al., 2015; Cho et al., 2016; Park et al., 2016). Further studies have concluded that the active form of PSY is given by the formation of the membrane-complex PSY-Orange, which is responsible for carotenogenesis (Welsch et al., 2018), while nonassociated, misfolded PSY is subject of degradation by Clp proteases; thus, Orange protein constitutes a key enzyme for the regulation of carotenoid synthesis (Chayut et al., 2017; Welsch et al., 2018).

The creation of a metabolic sink, via promoting the formation of carotenoid-sequestering structures, can additionally modulate carotenoid content (Li and Van Eck, 2007; Sun et al., 2018) and is also function of the Orange gene (Chayut et al., 2017). In B. oleracea, this mutation induces accumulation of 
high levels of $\beta$-carotene by elevated biogenesis of chromoplasts (Li and Yuan, 2013) up-regulating the plastid formation/ translocation factor gene ( $\mathrm{Lu}$ et al., 2006). Because of the evidence of the formation of the active membrane complex PSYOrange and its function on carotenoid formation, chromoplast differentiation in presence of the complex might be triggered by accumulation of carotenoids above the threshold required to stimulate plastid differentiation (Bai et al., 2014; Welsch et al., 2018). The influence of Orange affects not only nongreen tissue. Experiments in tomato showed that expression of AtOR ${ }^{H i s}$ also increased the content especially of $\beta$-carotene in tomato flowers and fruits (Yazdani et al., 2018), organs with a high carotenoid content. In absence of functional Orange protein (Chayut et al., 2017), chromoplast formation was inhibited as early as 30 days after anthesis, and the effect was maintained through fruit ripening, illustrating the temporal accumulation of $\beta$-carotene and lutein. In addition, Orange gene regulates plastid replications, so each cell contains a single chromoplast (Paolillo et al., 2004), densely packed with carotenoids.

Studies have demonstrated that total carotenoid content is also regulated by carotenoid degradation (Vallabhaneni and Wurtzel, 2009; Gayen et al., 2015). An inverse effect in Arabidopsis carotenoid content is given when there is a loss of function of the carotenoid cleavage dioxygenase 1 (CCD1) resulting in an increase in carotenoids (Auldridge et al., 2006). In later studies, it was well established that an increase in the number of CCD1 copies, leading to transcript accumulation during grain development, negatively correlated with maize seed carotenoid content (Vallabhaneni et al., 2010; da Silva Messias et al., 2014). Endosperm carotenoid content in maize varies widely from yellow to white, showing the highest CCD1 expression level in the latter, because of the action of multiple copies of CCD1 exhibiting carotenoid degrading activity, which are encoded by white cap locus (Tan et al., 2017). Likewise, loss of function in CCD4 induces carotenoid accumulation during grain maturation, resulting in an increase of eightfold in $\beta$-carotene content in Arabidopsis (da Silva Messias et al., 2014). In sweetpotato overexpressing $I b O R$, it was found that 9-cis-epoxycarotenoid dioxygenases, CCD1, and CCD4 were highly expressed and that Orange interacts specifically with CCD4, suggesting that Orange has an important role regulating carotenoid homeostasis by preventing degradation (Park et al., 2015). In melon, Orange-mediated $\beta$-carotene accumulation has been demonstrated to be the result of downstream metabolism inhibition (hydroxylation or degradation) (Chayut et al., 2017). This mechanism is species-dependent (Tzuri et al., 2015); previous studies have shown that overexpression of $\mathrm{CmOR}{ }^{\mathrm{His}}$ or $A t O R^{\text {His }}$ promotes $\beta$-carotene accumulation, along with significant amounts of lutein, in nongreen tissue of Arabidopsis (Tzuri et al., 2015). CmOR expression was positively correlated with chromoplast formation, having an important effect on the stability and metabolism of $\beta$-carotene, contributing with no effect on the carotenoid pathway reactions upstream of $\beta$-carotene formation (Chayut et al., 2015; Tzuri et al., 2015). Only expression of $\mathrm{CmOR}^{\mathrm{His}}$ prevented further degradation of carotenoid, resulting in accumulation in chromoplasts (Tzuri et al., 2015).

\section{MANIPULATING ORANGE GENE TOWARD CAROTENOID ACCUMULATION}

Low levels of carotenoid in major crops have led to efforts to increase its contents through the development of carotenoidenriched staple food (Fraser and Bramley, 2004). By altering the key biosynthesis and degradation gene levels, several crops with high carotenoid content have been developed (Fraser et al., 2002; Ducreux et al., 2004; Paine et al., 2005; Diretto et al., 2007a; Naqvi et al., 2009; Welsch et al., 2010). Overexpression of carotenoid PSY gene from bacteria or plants resulted in significant increases in total carotenoid levels in tomato fruits (Fraser et al., 2002), potato tubers (Ducreux et al., 2004), and canola seeds (Shewmaker et al., 1999). However, overexpression of PSY in canola and Arabidopsis led to a delay in germination because of an undesired collateral effect such as an increase in carotenoid-derived ABA (Shewmaker et al., 1999; Lindgren et al., 2003). In transgenic tomatoes, accumulation of PSY-1 resulted in limited growth due to insufficient gibberellin synthesis, as well as altered fruit pigmentation (Fray et al., 1995). Therefore, a different approach was followed in later experiments, by combining expression of different genes belonging to the carotenoid pathway, which led to substantial $\beta$-carotene increases in rice (Ye et al., 2000; Paine et al., 2005; Tian et al., 2019) and potato (Diretto et al., 2007a; Diretto et al., 2007b). A variation of the method was proven in maize; by selecting those favorable alleles that had been verified to alter the metabolic pathway toward $\beta$-carotene gave as an end result orange maize seeds with extended $\beta$-carotene content (Harjes et al., 2008; Yan et al., 2010; Zhu et al., 2018). However, in some cases, the increased flux into carotenoid biosynthesis can alter or reduce flux to other important pathways, leading to undesired changes (Cazzonelli and Pogson, 2010).

The manipulation of Orange genes (Table 1) provides an alternative and complementary strategy to increase carotenoid levels by increasing chromoplast differentiation (Li and Van Eck, 2007) and stabilizing PSY (Welsch et al., 2018). The expression of mutant $\mathrm{BoOR}$ in potato tubers gave an increase in carotenoid content (Lopez et al., 2008) contributing to potato tuber storage during postharvest conditions (Li et al., 2012). The sweetpotato ortholog, $I b O R$, induced carotenoid accumulation in sweetpotato callus, likely as a result of the formation of PSY-Orange complex, favoring carotenoid biosynthesis (Kim et al., 2013; Welsch et al., 2018). Carotenoid isomerase, lycopene cyclase B, and plastid fusion/translocation factor were highly expressed in the $I b O R$ transgenic calli, resulting in an increase of 12 -fold in total carotenoid content (Kim et al., 2013).

By mimicking the naturally occurring mutation in melon, where a single Arg to His substitution in Orange gene is responsible for the orange-fleshed phenotype (Tzuri et al., 2015), a change was introduced to Arabidopsis thaliana to generate $A t O R^{\text {His }}$ mutants, which were able to accumulate carotenoids in calli (Yuan et al., 2015a). From this finding, it was proven that the His mutation in Orange gene might change or create a new active center or binding site, leading to accumulation of carotenoids (Yuan et al., 2015a), broadening the possibilities of generating crops with enhanced carotenoid content. 
TABLE 1 | Effect of Orange gene on carotenoid expression in higher plants.

\begin{tabular}{|c|c|c|c|c|}
\hline Species gene donor & Host/organ & Mutation & Function & Reference \\
\hline Brassica oleracea & Solanum tuberosum/tubers & BoORMut & Carotenoid accumulation and chromoplast formation & (Lopez et al., 2008) \\
\hline B. oleracea & S. tuberosum/tubers & BoORMut & Stable carotenoid accumulation during postharvest & (Li et al., 2012) \\
\hline Ipomoea batatas & 1. batatas/callus & IbOR-Ins & Carotenoid accumulation Salt stress tolerance & (Kim et al., 2013) \\
\hline Arabidopsis thaliana & Oryza sativa/calli & AtOR ${ }^{H i s}$ & Carotenoid accumulation & (Bai et al., 2014) \\
\hline 1. batatas & Medicago sativa/leaves & IbOR-Ins & Carotenoid accumulation Abiotic stress tolerance & (Wang et al., 2015) \\
\hline Sorghum bicolor & A. thaliana/callus & SbOR His & Carotenoid accumulation & (Yuan et al., 2015a) \\
\hline Cucumis melon & A. thaliana/callus & $\mathrm{CmOR}$ & Carotenoid accumulation & (Tzuri et al., 2015) \\
\hline A. thaliana & O. sativa/seeds & AtOR ${ }^{H i s}$ & Carotenoid accumulation & (Bai et al., 2016) \\
\hline I. batatas & S. tuberosum/tubers & IbOR-Ins & Tuber yield Abiotic stress tolerance & (Cho et al., 2016) \\
\hline 1. batatas & A. thaliana/callus & IbOr-Ins & Abiotic stress tolerance & (Park et al., 2016) \\
\hline A. thaliana & Zea mays/seeds & AtOR ${ }^{\text {His }}$ & Carotenoid accumulation & (Berman et al., 2017) \\
\hline A. thaliana & Solanum licopersicum/fruit & AtOR ${ }^{\text {His }}$ & Carotenoid accumulation & (Yazdani et al., 2018) \\
\hline M. sativa & Nicotiana benthamiana/leaves & MsOr & Carotenoid accumulation/environmental stress tolerance & (Wang et al., 2018) \\
\hline
\end{tabular}

The expression of AtOR also induced carotenoid accumulation in rice callus (Bai et al., 2014) and seeds (Bai et al., 2016). In this latter case, expression of three genes involved in carotenoid synthesis was achieved. Arabidopsis thaliana Orange (AtOR) gene, which was shown to successfully sequester carotenoids in rice callus, was expressed under control of an specific endosperm promoter, along with two carotenogenic genes, Zea mays phytoene synthase1 (ZmPSY1) and Pantoea ananatis phytoene desaturase ( $P a C R T I$ ) (Bai et al., 2014). In the experiment, combined expression of ZmPSY1, $P a C R T I$, and AtOR enhanced carotenoid increase through the creation of a metabolic sink, which resulted in the positive regulation of several endogenous carotenogenic genes (Bai et al., 2014). Measurement of total carotenoid content when all three genes were expressed (AtOR, ZmPSY1, and PaCRTI) resulted in an increase of at least twofold of carotenoid levels, with prevalence of higher levels of $\beta$-carotene and $\alpha$ carotene (Bai et al., 2014). In a different experiment, the level of endogenous Oryza sativa lycopene cyclase- $\beta$ (OsLCY- $\beta$ ) increased in rice lines expressing AtOR, suggesting endogenous $O s L C Y-\beta$ is sufficient for enhanced $\beta$-carotene synthesis and accumulation in lines overexpressing 1-deoxy--xylulose 5 -phosphate synthase as might be expected given the greater presence throughout the entire pathway (Bai et al., 2016). This situation can be explained by the level of endogenous $O s L C Y-\varepsilon$ mRNA, which was positively regulated in those lines expressing $A t O R$, resulting in a fivefold increase in $\alpha$-carotene accumulation in seeds (Bai et al., 2016).

In a later experiment, expression of AtOR under the control of an endosperm-specific wheat low-molecular-weight glutenin promoter resulted in an elevated carotenoid content in white corn (Berman et al., 2017), by promoting the formation of carotenoid-sequestering plastoglobuli when the carotenoid pool was limited, but it had no effect when carotenoid levels where abundant, in which case carotenoid storage structures can be induced even in the absence of AtOR (Berman et al., 2017). On the other hand, in transgenic tomato, overexpression of $A t O R^{\mathrm{His}}$ mutant enhanced the accumulation of carotenoids in nongreen tissue by promoting chloroplast to chromoplast conversion and induced carotenoid accumulation at early fruit developmental stages (Yazdani et al., 2018), when using Cauliflower mosaic virus $35 \mathrm{~S}$ as promoter; therefore, further research is needed to elucidate the role of promoters in Orange gene expression and carotenoid content. In addition to these findings, it was found that $A t O R^{\mathrm{His}}$ mutant promoted early flowering, fruit set, and seed production, three agronomically important characters for increasing fruit yield as well as to develop varieties adapted to harsh conditions such as chill injury or short summer season (Yazdani et al., 2018),

Besides to their role in carotenoid accumulation, $O R$ genes have been shown to enhance tolerance to environmental stress. In sweetpotato, overexpression of $I b O R$ enhanced tolerance to heat and oxidative stress (Park et al., 2016; Kang et al., 2017). Transgenic alfalfa and potato overexpressing $I b O R$ showed a remarkable resistance to a variety of abiotic stresses, such as drought, salinity, and heat (Wang et al., 2015; Cho et al., 2016). Transcriptome analysis at early fruit development in tomato showed that eight common genes at $A t O R^{\text {His }}$ were heat shock proteins, supporting the hypothesis that Orange might play an important role during heat stress (Yazdani et al., 2018); however, because of the lack of $\mathrm{J}$ domain on the protein, Orange protein mode of action is proposed to be by interaction with the substrate by the Zinc finger and C-terminal domain (Pulido and Leister, 2018), and therefore, expression of Orange proteins can be linked to photosynthesis maintenance, by increase in carotenoid levels by enhancing sink strength in storage tissues leads to stress tolerance in plants (Wang et al., 2015; Cho et al., 2016; Kim et al., 2018; Wang et al., 2018).

\section{PROPOSED STRATEGIES TO MODIFY ORANGE GENE}

The advent of the highly efficient CRISPR/Cas9 system for eukaryote gene editing (Jinek et al., 2012; Cong et al., 2013), with rice being the first edited plant genome (Zhang et al., 2014; Zhang et al., 2016), opened the possibility to mutate target genes in crop species (Shan et al., 2013). Utilization of CRISPR/Cas9 complex to generate double-stranded breaks under the specific guidance of a single guide RNA provides 
the opportunity to mutate the gene of interest to produce desire effect on the progeny (Scheben et al., 2017). Originally designed to rely on homologous recombination, or more commonly, on nonhomologous end-joining, to lead the introduction of mutations such as small insertions or deletions in the targeted DNA molecules (Jinek et al., 2012; Cong et al., 2013), the increasing need to incorporate specific mutations for genome editing in plants has headed to the development of novel techniques, such as "base editor" (Hua et al., 2018; Kang et al., 2018; Li et al., 2018; Yan et al., 2018; Qin et al., 2019). Successful edition of GhCLA and GhPEBP by a base editor consisting of a cytidine deamidase domain fused with nCas9 and UGI resulted in a $57 \%$ of base-editing efficiency with no detectable unwanted mutations on the progeny (Qin et al., 2019). This development offers advantageous possibilities to mutate Orange to increase carotenoid accumulation in crop species, taking advantage of His/Ala mutation (Yuan et al., 2015a; Yuan et al., 2015b) at conserved Arginine residue, and also to explore the function of residues at Zinc finger domain and the rationale behind PSY stabilization.

Nevertheless, optimization of CRISPR technology is also needed for each species to accommodate the tissue and transformation delivery method (Char et al., 2017). Today, two major transformation methods are utilized for DNA delivery, Agrobacterium tumefaciens or biolistic transformation (genegun), with both methods being effective in transforming different plant species, with Agrobacterium based-method, being more popular and efficient for the insertion of low numbers of transgenes (Khatodia et al., 2016; Char et al., 2017). Lately, the development of new transformation techniques based on the utilization of functionalized nanoparticles to deliver DNA has been proven with success in species such as cotton, sunflower, and lily (Zhao et al., 2017). With the aid of magnetic fields, nanoparticles can efficiently deliver CRISPR vectors through pores present in the pollen grains, producing transformed pollen, which is then used to pollinate emasculated flowers, resulting in transformed seeds (Zhao et al., 2017). This increases transformation efficiency and bypasses the procedure of tissue culture to generate plants from transformed seeds within a short period of time, allowing the introduction of functional alleles of Orange into staple crops, contributing to existing breeding programs worldwide.

\section{REFERENCES}

Auldridge, M. E., Block, A., Vogel, J. T., Dabney-Smith, C., Mila, I., Bouzayen, M., et al. (2006). Characterization of three members of the Arabidopsis carotenoid cleavage dioxygenase family demonstrates the divergent roles of this multifunctional enzyme family. Plant J. 45 (6), 982-993. doi: 10.1111/j.1365-313X.2006.02666.X

Bai, C., Capell, T., Berman, J., Medina, V., Sandmann, G., Christou, P., et al. (2016). Bottlenecks in carotenoid biosynthesis and accumulation in rice endosperm are influenced by the precursor-product balance. Plant Biotechnol. J. 14 (1), 195-205. doi: 10.1111/pbi.12373

Bai, C., Rivera, S. M., Medina, V., Alves, R., Vilaprinyo, E., Sorribas, A., et al. (2014). An in vitro system for the rapid functional characterization of genes involved in carotenoid biosynthesis and accumulation. Plant J. 77 (3), 464-475. doi: $10.1111 /$ tpj. 12384

\section{CONCLUSION AND FUTURE PROSPECTS}

To date, despite the evidence that supports Orange protein playing an important role in plant growth and development, only a few species have characterized the gene, including cauliflower, Arabidopsis, melon, sweetpotato, and alfalfa. Orange represents an exceptional class of regulatory genes that mediate carotenoid accumulation, being highly conserved among different species, with critical functions, such as maintaining carotenoid homeostasis and acting directly under environmental stress, controlling carotenoid biosynthesis, and stabilizing photosynthesis.

Further examination of the $O R$ effects in different species and its diversity among them will help to elucidate fully the functional role of this gene, allowing its manipulation to enhance $\beta$-carotene levels. With the advent of genome editing techniques, which can direct specific point mutations in the genome, there are certain possibilities to modify the Orange gene sequence to increase carotenoid accumulation in staple crop species such as wheat, corn, canola, and rice by nontransgenic approach. There is enough evidence to support that Orange genes could be used to cope with the effects of climate change; therefore, its manipulation could be suitable to use in strategic crops, widely distributed, to develop varieties with increased tolerance to heat and water stress, in addition to improved nutritional qualities associated with higher levels of carotenoids.

\section{AUTHOR CONTRIBUTIONS}

CO developed the idea and wrote the manuscript.

\section{FUNDING}

The author thanks financial support from CONICYT REGIONAL/ GORE ARAUCANIA/ CGNA R16A10001.

\section{ACKNOWLEDGMENTS}

The author thanks the editor and reviewers for the valuable time and suggestions to make this article better.

Beatty, S., Koh, H.-H., Phil, M., Henson, D., and Boulton, M. (2000). The role of oxidative stress in the pathogenesis of age-related macular degeneration. Surv. Ophthalmol. 45 (2), 115-134. doi: 10.1016/S0039-6257(00)00140-5

Berman, J., Zorrilla-López, U., Medina, V., Farré, G., Sandmann, G., Capell, T., et al. (2017). The Arabidopsis Orange (AtOR) gene promotes carotenoid accumulation in transgenic corn hybrids derived from parental lines with limited carotenoid pools. Plant Cell Rep. 36 (6), 933-945. doi: 10.1007/ s00299-017-2126-z

Cazzonelli, C. I., and Pogson, B. J. (2010). Source to sink: regulation of carotenoid biosynthesis in plants. Trends Plant Sci. 15 (5), 266-274. doi: 10.1016/j. tplants.2010.02.003

Char, S. N., Neelakandan, A. K., Nahampun, H., Frame, B., Main, M., Spalding, M. H., et al. (2017). An Agrobacterium-delivered CRISPR/Cas9 system for highfrequency targeted mutagenesis in maize. Plant Biotechnol. J. 15 (2), 257-268. doi: $10.1111 /$ pbi.12611 
Chayut, N., Yuan, H., Ohali, S., Meir, A., Sa’ar, U., Tzuri, G., et al. (2017). Distinct mechanisms of the Orange protein in controlling carotenoid flux. Plant Physiol. 173 (1), 376-389. doi: 10.1104/pp.16.01256.

Chayut, N., Yuan, H., Ohali, S., Meir, A., Yeselson, Y., Portnoy, V., et al. (2015). A bulk segregant transcriptome analysis reveals metabolic and cellular processes associated with Orange allelic variation and fruit $\beta$-carotene accumulation in melon fruit. BMC Plant Biol. 15 (1), 274. doi: 10.1186/s12870-015-0661-8.

Cho, K.-S., Han, E.-H., Kwak, S.-S., Cho, J.-H., Im, J.-S., Hong, S.-Y., et al. (2016). Expressing the sweet potato orange gene in transgenic potato improves drought tolerance and marketable tuber production. C. R. Biol. 339 (5-6), 207-213. doi: 10.1016/j.crvi.2016.04.010.

Cong, L., Ran, F. A., Cox, D., Lin, S., Barretto, R., Habib, N., et al. (2013). Multiplex genome engineering using CRISPR/Cas systems. Science 339 (6121), 819-823. doi: $10.1126 /$ science.1231143.

Cong, L., Wang, C., Chen, L., Liu, H., Yang, G., and He, G. (2009). Expression of phytoene synthase 1 and carotene desaturase crtI genes result in an increase in the total carotenoids content in transgenic elite wheat (Triticum aestivum L.). J. Agric. Food Chem. 57 (18), 8652-8660. doi: 10.1021/jf9012218

Crozier, A.,Kamiya, Y., Bishop, G.,Yokota, T. (2000). Biosynthesis of hormones and elicitor molecules. In: Biochemistry and Molecular Biology of Plants, B.B. Buchanan, W. Cruissem and R.L. Jones, eds (Rockville, MD: American Society of Plant Physiologists), 850-929.

da Silva Messias, R., Galli, V., dos Anjos e Silva, S. D., and Rombaldi, C. V. (2014). Carotenoid biosynthetic and catabolic pathways: gene expression and carotenoid content in grains of maize landraces. Nutrients 6 (2), 546-563. doi: $10.3390 /$ nu6020546

Diretto, G., Al-Babili, S., Tavazza, R., Papacchioli, V., Beyer, P., and Giuliano, G. (2007a). Metabolic engineering of potato carotenoid content through tuberspecific overexpression of a bacterial mini-pathway. PLoS One 2 (4), e350. doi: 10.1371/journal.pone.0000350

Diretto, G., Welsch, R., Tavazza, R., Mourgues, F., Pizzichini, D., Beyer, P., et al. (2007b). Silencing of beta-carotene hydroxylase increases total carotenoid and beta-carotene levels in potato tubers. BMC Plant Biol. 7 (1), 11. doi: 10.1186/1471-2229-7-11.

Domonkos, I., Kis, M., Gombos, Z., and Ughy, B. (2013). Carotenoids, versatile components of oxygenic photosynthesis. Prog. Lipid Res. 52 (4), 539-561. doi: 10.1016/j.plipres.2013.07.001.

Ducreux, L. J., Morris, W. L., Hedley, P. E., Shepherd, T., Davies, H. V., Millam, S., et al. (2004). Metabolic engineering of high carotenoid potato tubers containing enhanced levels of $\beta$-carotene and lutein. J. Exp. Bot. 56 (409), 81-89. doi: 10.1093/jxb/eri016.

Fiedor, J., and Burda, K. (2014). Potential role of carotenoids as antioxidants in human health and disease. Nutrients 6 (2), 466-488. doi: 10.3390/nu6020466.

Fraser, P. D., and Bramley, P. M. (2004). The biosynthesis and nutritional uses of carotenoids. Prog. Lipid Res. 43 (3), 228-265. doi: 10.1016/j.plipres.2003.10.002.

Fraser, P. D., Romer, S., Shipton, C. A., Mills, P. B., Kiano, J. W., Misawa, N., et al. (2002). Evaluation of transgenic tomato plants expressing an additional phytoene synthase in a fruit-specific manner. Proc. Natl. Acad. Sci. 99 (2), 1092-1097. doi: 10.1073/pnas.241374598.

Fray, R. G., Wallace, A., Fraser, P. D., Valero, D., Hedden, P., Bramley, P. M., et al. (1995). Constitutive expression of a fruit phytoene synthase gene in transgenic tomatoes causes dwarfism by redirecting metabolites from the gibberellin pathway. Plant J. 8 (5), 693-701. doi: 10.1046/j.1365-313X.1995.08050693.x.

Gayen, D., Ali, N., Sarkar, S. N., Datta, S. K., and Datta, K. (2015). Down-regulation of lipoxygenase gene reduces degradation of carotenoids of golden rice during storage. Planta 242 (1), 353-363. doi: 10.1007/s00425-015-2314-4.

Gomez-Roldan, V., Fermas, S., Brewer, P. B., Puech-Pagès, V., Dun, E. A., Pillot, J.-P., et al. (2008). Strigolactone inhibition of shoot branching. Nature 455 (7210), 189. doi: 10.1038/nature07271.

Harjes, C. E., Rocheford, T. R., Bai, L., Brutnell, T. P., Kandianis, C. B., Sowinski, S. G., et al. (2008). Natural genetic variation in lycopene epsilon cyclase tapped for maize biofortification. Science 319 (5861), 330-333. doi: 10.1126/science.1150255.

Howitt, C. A., and Pogson, B. J. (2006). Carotenoid accumulation and function in seeds and non-green tissues. Plant Cell Environ. 29 (3), 435-445. doi: 10.1111/j.1365-3040.2005.01492.x

Hua, K., Tao, X., Yuan, F., Wang, D., and Zhu, J.-K. (2018). Precise A. T to G. $\mathrm{C}$ base editing in the rice genome. Mol. Plant 11 (4), 627-630. doi: 10.1016/j. molp.2018.02.007
Hughes, D. A. (1999). Effects of carotenoids on human immune function. Proc. Nutr. Soc. 58 (3), 713-718. doi: 10.1017/S0029665199000932

Jinek, M., Chylinski, K., Fonfara, I., Hauer, M., Doudna, J. A., and Charpentier, E. (2012). A programmable dual-RNA-guided DNA endonuclease in adaptive bacterial immunity. Science 337 (6096), 816-821. doi: 10.1126/science.1225829

Kang, B.-C., Yun, J.-Y., Kim, S.-T., Shin, Y., Ryu, J., Choi, M., et al. (2018). Precision genome engineering through adenine base editing in plants. Nat. Plants 4 (7), 427. doi: 10.1038/s41477-018-0178-x

Kang, L., Kim, H. S., Kwon, Y. S., Ke, Q., Ji, C. Y., Park, S.-C., et al. (2017). IbOr regulates photosynthesis under heat stress by stabilizing IbPsbP in sweetpotato. Front. Plant Sci. 8, 989. doi: 10.3389/fpls.2017.00989

Khatodia, S., Bhatotia, K., Passricha, N., Khurana, S., and Tuteja, N. (2016). The CRISPR/Cas genome-editing tool: application in improvement of crops. Front. Plant Sci. 7, 506. doi: 10.3389/fpls.2016.00506

Kim, H. S., Ji, C. Y., Lee, C.-J., Kim, S.-E., Park, S.-C., and Kwak, S.-S. (2018). Orange: a target gene for regulating carotenoid homeostasis and increasing plant tolerance to environmental stress in marginal lands. J. Exp. Bot. 69 (14), 3393-3400. doi: 10.1093/jxb/ery023

Kim, S. H., Ahn, Y. O., Ahn, M.-J., Jeong, J. C., Lee, H.-S., and Kwak, S.-S. (2013). Cloning and characterization of an Orange gene that increases carotenoid accumulation and salt stress tolerance in transgenic sweetpotato cultures. Plant Physiol. Biochem. 70, 445-454. doi: 10.1016/j.plaphy.2013.06.011

Li, C., Zong, Y., Wang, Y., Jin, S., Zhang, D., Song, Q., et al. (2018). Expanded base editing in rice and wheat using a Cas9-adenosine deaminase fusion. Genome Biol. 19 (1), 59. doi: 10.1186/s13059-018-1443-z

Li, F., Vallabhaneni, R., and Wurtzel, E. T. (2008a). PSY3, a new member of the phytoene synthase gene family conserved in the Poaceae and regulator of abiotic stress-induced root carotenogenesis. Plant Physiol. 146 (3), 1333-1345. doi: 10.1104/pp.107.111120

Li, F., Vallabhaneni, R., Yu, J., Rocheford, T., and Wurtzel, E. T. (2008b). The maize phytoene synthase gene family: overlapping roles for carotenogenesis in endosperm, photomorphogenesis, and thermal stress tolerance. Plant Physiol. 147 (3), 1334-1346. doi: 10.1104/pp.108.122119

Li, L., Paolillo, D. J., Parthasarathy, M. V., DiMuzio, E. M., and Garvin, D. F. (2001). A novel gene mutation that confers abnormal patterns of $\beta$-carotene accumulation in cauliflower (Brassica oleracea var. botrytis). Plant J. 26 (1), 59-67. doi: 10.1046/j.1365-313x.2001.01008.x

Li, L., and Van Eck, J. (2007). Metabolic engineering of carotenoid accumulation by creating a metabolic sink. Transgenic Res. 16 (5), 581-585. doi: 10.1007/ s11248-007-9111-1

Li, L., Yang, Y., Xu, Q., Owsiany, K., Welsch, R., Chitchumroonchokchai, C., et al. (2012). The Or gene enhances carotenoid accumulation and stability during postharvest storage of potato tubers. Mol. Plant 5 (2), 339-352. doi: 10.1093/mp/ssr099

Li, L., and Yuan, H. (2013). Chromoplast biogenesis and carotenoid accumulation. Arch. Biochem. Biophys. 539 (2), 102-109. doi: 10.1016/j.abb.2013.07.002

Lindgren, L. O., Stålberg, K. G., and Höglund, A.-S. (2003). Seed-specific overexpression of an endogenous Arabidopsis phytoene synthase gene results in delayed germination and increased levels of carotenoids, chlorophyll, and abscisic acid. Plant Physiol. 132 (2), 779-785. doi: 10.1104/pp.102.017053

Lopez, A. B., Van Eck, J., Conlin, B. J., Paolillo, D. J., O'neill, J., and Li, L. (2008). Effect of the cauliflower Or transgene on carotenoid accumulation and chromoplast formation in transgenic potato tubers. J. Exp. Bot. 59 (2), 213-223. doi: 10.1093/jxb/erm299

Lu, S., Van Eck, J., Zhou, X., Lopez, A. B., O'Halloran, D. M., Cosman, K. M., et al. (2006). The cauliflower Or gene encodes a DnaJ cysteine-rich domaincontaining protein that mediates high levels of $\beta$-carotene accumulation. Plant Cell 18 (12), 3594-3605. doi: 10.1105/tpc.106.046417

Naqvi, S., Zhu, C., Farre, G., Ramessar, K., Bassie, L., Breitenbach, J., et al. (2009). Transgenic multivitamin corn through biofortification of endosperm with three vitamins representing three distinct metabolic pathways. Proc. Natl. Acad. Sci. 106 (19), 7762-7767. doi: 10.1073/pnas.0901412106

Nisar, N., Li, L., Lu, S., Khin, N. C., and Pogson, B. J. (2015). Carotenoid metabolism in plants. Mol. Plant 8 (1), 68-82. doi: 10.1016/j.molp.2014.12.007

Niyogi, K. K., and Truong, T. B. (2013). Evolution of flexible non-photochemical quenching mechanisms that regulate light harvesting in oxygenic photosynthesis. Curr. Opin. Plant Biol. 16 (3), 307-314. doi: 10.1016/j. pbi.2013.03.011 
Paine, J. A., Shipton, C. A., Chaggar, S., Howells, R. M., Kennedy, M. J., Vernon, G., et al. (2005a). Improving the nutritional value of golden rice through increased pro-vitamin A content. Nat. Biotechnol. 23 (4), 482. doi: 10.1038/nbt1082

Paolillo, D., Garvin, D., and Parthasarathy, M. (2004). The chromoplasts of Or mutants of cauliflower (Brassica oleracea L. var. botrytis). Protoplasma 224 (3-4), 245-253. doi: 10.1007/s00709-004-0059-1.

Park, S., Kim, H. S., Jung, Y. J., Kim, S. H., Ji, C. Y., Wang, Z., et al. (2016). Orange protein has a role in phytoene synthase stabilization in sweetpotato. Sci. Rep. 6, 33563. doi: $10.1038 /$ srep 33563

Park, S.-C., Kim, S. H., Park, S., Lee, H.-U., Lee, J. S., Park, W. S., et al. (2015). Enhanced accumulation of carotenoids in sweetpotato plants overexpressing IbOr-Ins gene in purple-fleshed sweetpotato cultivar. Plant Physiol. Biochem. 86, 82-90. doi: 10.1016/j.plaphy.2014.11.017

Pulido, P., and Leister, D. (2018). Novel DNAJ-related proteins in Arabidopsis thaliana. New Phytol. 217 (2), 480-490. doi: 10.1111/nph.14827.

Qin, L., Li, J., Wang, Q., Xu, Z., Sun, L., Alariqi, M., et al. (2019). High efficient and precise base editing of $\mathrm{C} \cdot \mathrm{G}$ to $\mathrm{T} \bullet \mathrm{A}$ in the allotetraploid cotton (Gossypium hirsutum) genome using a modified CRISPR/Cas9 system. Plant Biotechnol. J. 1-12. doi: $10.1111 /$ pbi.13168

Ramel, F., Birtic, S., Ginies, C., Soubigou-Taconnat, L., Triantaphylidès, C., and Havaux, M. (2012). Carotenoid oxidation products are stress signals that mediate gene responses to singlet oxygen in plants. Proc. Natl. Acad. Sci. 109 (14), 5535-5540. doi: 10.1073/pnas.1115982109

Scheben, A., Wolter, F., Batley, J., Puchta, H., and Edwards, D. (2017). Towards CRISPR/Cas crops-bringing together genomics and genome editing. New Phytol. 216 (3), 682-698. doi: 10.1111/nph.14702

Seddon, J. M., Ajani, U. A., Sperduto, R. D., Hiller, R., Blair, N., Burton, T. C., et al. (1994). Dietary carotenoids, vitamins $\mathrm{A}, \mathrm{C}$, and $\mathrm{E}$, and advanced age-related macular degeneration. Jama 272 (18), 1413-1420. doi: 10.1001/jama.1994.03520180037032

Shan, Q., Wang, Y., Li, J., Zhang, Y., Chen, K., Liang, Z., et al. (2013). Targeted genome modification of crop plants using a CRISPR-Cas system. Nat. Biotechnol. 31 (8), 686-688. doi: 10.1038/nbt.2650

Shewmaker, C. K., Sheehy, J. A., Daley, M., Colburn, S., and Ke, D. Y. (1999). Seedspecific overexpression of phytoene synthase: increase in carotenoids and other metabolic effects. Plant J. 20 (4), 401-412. doi: 10.1046/j.1365-313x.1999.00611.x

Snodderly, D. M. (1995). Evidence for protection against age-related macular degeneration by carotenoids and antioxidant vitamins. Am. J. Clin. Nutr. 62 (6), 1448S-1461S. doi: 10.1093/ajcn/62.6.1448S

Sun, T., Yuan, H., Cao, H., Yazdani, M., Tadmor, Y., and Li, L. (2018). Carotenoid metabolism in plants: the role of plastids. Mol. Plant 11 (1), 58-74. doi: 10.1016/j.molp.2017.09.010

Sun, T.-H., Zhou, F., Liu, C.-J., Zhuang, Z., and Lu, S. (2016). The DnaJ-like zinc finger domain protein Orange localizes to the nucleus in etiolated cotyledons of Arabidopsis thaliana. Protoplasma 253 (6), 1599-1604. doi: 10.1007/s00709-015-0919-x.

Tan, B.-C., Guan, J.-C., Ding, S., Wu, S., Saunders, J. W., Koch, K. E., et al. (2017). Structure and origin of the white cap locus and its role in evolution of grain color in maize. Genetics 206 (1), 135-150. doi: 10.1534/genetics.116.198911

Tian, Y. S., Wang, B., Peng, R. H., Xu, J., Li, T., Fu, X. Y., et al. (2019). Enhancing carotenoid biosynthesis in rice endosperm by metabolic engineering. Plant Biotechnol. J. 17 (5), 849. doi: 10.1111/pbi.13059.

Tzuri, G., Zhou, X., Chayut, N., Yuan, H., Portnoy, V., Meir, A., et al. (2015). A 'golden' SNP in CmOr governs the fruit flesh color of melon (Cucumis melo). Plant J. 82 (2), 267-279. doi: 10.1111/tpj.12814

Vallabhaneni, R., Bradbury, L. M., and Wurtzel, E. T. (2010). The carotenoid dioxygenase gene family in maize, sorghum, and rice. Arch. Biochem. Biophys. 504 (1), 104-111. doi: 10.1016/j.abb.2010.07.019

Vallabhaneni, R., and Wurtzel, E. T. (2009). Timing and biosynthetic potential for carotenoid accumulation in genetically diverse germplasm of maize. Plant Physiol. 150 (2), 562-572. doi: 10.1104/pp.109.137042

Wang, Z., Ke, Q., Kim, M. D., Kim, S. H., Ji, C. Y., Jeong, J. C., et al. (2015). Transgenic alfalfa plants expressing the sweetpotato Orange gene exhibit enhanced abiotic stress tolerance. PLoS One 10 (5), e0126050. doi: 10.1371/journal.pone.0126050

Wang, Z., Xu, W., Kang, J., Li, M., Huang, J., Ke, Q., et al. (2018). Overexpression of alfalfa Orange gene in tobacco enhances carotenoid accumulation and tolerance to multiple abiotic stresses. Plant Physiol. Biochem. 130, 613-622. doi: 10.1016/j.plaphy.2018.08.017

Welsch, R., Arango, J., Bär, C., Salazar, B., Al-Babili, S., Beltrán, J., et al. (2010). Provitamin A accumulation in cassava (Manihot esculenta) roots driven by a single nucleotide polymorphism in a phytoene synthase gene. Plant Cell. 22, 3348-3356. doi: 10.1105/tpc.110.077560

Welsch, R., Zhou, X., Yuan, H., Álvarez, D., Sun, T., Schlossarek, D., et al. (2018). Clp protease and OR directly control the proteostasis of phytoene synthase, the crucial enzyme for carotenoid biosynthesis in Arabidopsis. Mol. Plant 11 (1), 149-162. doi: 10.1016/j.molp.2017.11.003

Yahia, E. M., de Jesús Ornelas-Paz, J., Emanuelli, T., Jacob-Lopes, E., Zepka, L. Q., and Cervantes-Paz, B. (2017). Chemistry, stability, and biological actions of carotenoids. Fruit Vegetable Phytochem: Chem. Hum. Health 2, 285. doi: 10.1002/9781119158042.ch15

Yan, F., Kuang, Y., Ren, B., Wang, J., Zhang, D., Lin, H., et al. (2018). Highly efficient A. $\mathrm{T}$ to $\mathrm{G} \cdot \mathrm{C}$ base editing by Cas9n-guided tRNA adenosine deaminase in rice. Mol. Plant 11 (4), 631-634. doi: 10.1016/j.molp.2018.02.008

Yan, J., Kandianis, C. B., Harjes, C. E., Bai, L., Kim, E.-H., Yang, X., et al. (2010). Rare genetic variation at Zea mays crtRB1 increases $\beta$-carotene in maize grain. Nat. Genet. 42 (4), 322. doi: 10.1038/ng.551

Yazdani, M., Sun, Z., Yuan, H., Zeng, S., Thannhauser, T. W., Vrebalov, J., et al. (2018). Ectopic expression of Orange promotes carotenoid accumulation and fruit development in tomato. Plant Biotechnol. J. 17 (1), 33-49. doi: 10.1111/pbi.12945

Ye, X., Al-Babili, S., Klöti, A., Zhang, J., Lucca, P., Beyer, P., et al. (2000). Engineering the provitamin A ( $\beta$-carotene) biosynthetic pathway into (carotenoid-free) rice endosperm. Science 287 (5451), 303-305. doi: 10.1126/science.287.5451.303

Yoneyama, K., Mori, N., Sato, T., Yoda, A., Xie, X., Okamoto, M., et al. (2018). Conversion of carlactone to carlactonoic acid is a conserved function of MAX 1 homologs in strigolactone biosynthesis. New Phytol. 218 (4), 1522-1533. doi: $10.1111 /$ nph.15055

Young, A. J., and Pallett, K. E., (2017). "Carotenoids," in Antioxidants in higher plants (CRC Press), 59-89. doi: 10.1201/9781315149899-3.

Yuan, H., Owsiany, K., Sheeja, T., Zhou, X., Rodriguez, C., Li, Y., et al. (2015a). A single amino acid substitution in an Orange protein promotes carotenoid overaccumulation in Arabidopsis. Plant Physiol. 169 (1), 421-431. doi: 10.1104/ pp.15.00971

Yuan, H., Zhang, J., Nageswaran, D., and Li, L. (2015b). Carotenoid metabolism and regulation in horticultural crops. Hortic. Res. 2, 15036. doi: 10.1038/ hortres.2015.36

Zhang, H., Zhang, J., Wei, P., Zhang, B., Gou, F., Feng, Z., et al. (2014). The CRISPR/ Cas9 system produces specific and homozygous targeted gene editing in rice in one generation. Plant Biotechnol. J. 12 (6), 797-807. doi: 10.1111/pbi.12200

Zhang, Z., Mao, Y., Ha, S., Liu, W., Botella, J. R., and Zhu, J.-K. (2016). A multiplex CRISPR/Cas9 platform for fast and efficient editing of multiple genes in Arabidopsis. Plant Cell Rep. 35, 1519-1533. doi: 10.1007/s00299-015-1900-Z

Zhao, X., Meng, Z., Wang, Y., Chen, W., Sun, C., Cui, B., et al. (2017). Pollen magnetofection for genetic modification with magnetic nanoparticles as gene carriers. Nat. Plants 3 (12), 956. doi: 10.1038/s41477-017-0063-z

Zhou, X., Sun, T. H., Wang, N., Ling, H. Q., Lu, S., and Li, L. (2011). The cauliflower Orange gene enhances petiole elongation by suppressing expression of eukaryotic release factor 1. New Phytol. 190 (1), 89-100. doi: 10.1111/j.1469-8137.2010.03578.x

Zhou, X., Welsch, R., Yang, Y., Álvarez, D., Riediger, M., Yuan, H., et al. (2015). Arabidopsis OR proteins are the major posttranscriptional regulators of phytoene synthase in controlling carotenoid biosynthesis. Proc. Natl. Acad. Sci. 112 (11), 3558-3563. doi: 10.1073/pnas. 1420831112

Zhu, C., Farré, G., Zanga, D., Lloveras, J., Michelena, A., Ferrio, J., et al. (2018). High-carotenoid maize: development of plant biotechnology prototypes for human and animal health and nutrition. Phytochem. Rev. 17 (2), 195-209. doi: $10.1007 /$ s11101-017-9506-4

Conflict of Interest: The author declares that the research was conducted in the absence of any commercial or financial relationships that could be construed as a potential conflict of interest.

Copyright (c) 2019 Osorio. This is an open-access article distributed under the terms of the Creative Commons Attribution License (CC BY). The use, distribution or reproduction in other forums is permitted, provided the original author(s) and the copyright owner(s) are credited and that the original publication in this journal is cited, in accordance with accepted academic practice. No use, distribution or reproduction is permitted which does not comply with these terms. 